\title{
Brittle fracture resistance and damping properties of layered metal-polymer composites
}

\author{
S. V. Kuteneva ${ }^{\dagger}$ S. V. Gladkovsky, D. I. Vichuzhanin, P. D. Nedzvetsky \\ †esv@imach.uran.ru
}

Institute of Engineering Science, UB of the RAS, Ekaterinburg, 620049, Russia

One of the topical trends in modern materials science is the development and study of new layered metal-polymer composites, which are increasingly used in aerospace engineering, automotive and transport engineering. The metal base of these composites provides a high level of strength properties and impact strength, and the polymer interlayer allows obtaining high damping properties due to its ability to dissipate the energy of elastic vibrations. Of a considerable practical interest is one of the varieties of metal-polymer composite materials based on a sandwich structure - layered steel-rubber composite characterized by pronounced viscoelastic properties, which allows them to be used as vibration damping elements in transport systems. In this work, the possibility of obtaining promising layered metal-rubber composites based on low-carbon steels (Fe-2Mn-1Si steel, IF steel), aluminum alloy Al-Mg3 and heat-and-frost-resistant rubber V-14-1NTA by hot pressing is studied. The influence of the composition and design of composites on the impact strength at temperatures of 20 and $-60^{\circ} \mathrm{C}$ and the damping ability characteristics of materials such as the tangent of the angle of mechanical losses $(\operatorname{tg} \delta)$, the modulus of elasticity $\left(E^{\prime}\right)$ and the modulus of viscosity $\left(E^{\prime \prime}\right)$ are determined by the method of dynamic mechanical analysis. The possibility of using layered metal-rubber composites with increased resistance to brittle fracture in the region of low climatic temperatures, as well as in structural elements of transport systems with high vibration resistance is shown.

Keywords: layered metal-rubber composite, hot pressing, impact strength, cyclic loading, dynamic mechanical analysis, damping.

УДК: 621.792.4-053:620.178.746.22:539.67

\section{Сопротивление хрупкому разрушению и демпфирующие свойства слоистых металлополимерных композитов}

\author{
С. В. Кутенева ${ }^{\dagger}$ С. В. Гладковский, Д. И. Вичужанин, П. Д. Недзвецкий \\ Институт машиноведения УрО РАН, Екатеринбург, 620049, Россия
}

Одним из актуальных направлений развития современного материаловедения является разработка и исследование новых слоистых металлополимерных композитов, которые находят все более широкое применение в авиакосмической технике, автомобилестроении и транспортном машиностроении. Металлическая основа данных композитов обеспечивает высокий уровень прочностных свойств и ударной вязкости, а полимерная прослойка позволяет получить высокие демпфирующие свойства, благодаря своей способности к диссипации энергии упругих колебаний, а также за счет низкой плотности полимерной составляющей возможно снизить вес конструкций. Значительный практический интерес представляет одна из разновидностей металлополимерных композиционных материалов на основе сэндвич-структуры - слоистые композиты типа «сталь-резина», характеризующиеся ярко выраженными вязкоупругими свойствами, что позволяет применять их в качестве вибродемпфирующих элементов в транспортных системах. В связи с этим в работе изучена возможностью получения перспективных слоистых металлорезиновых композитов на основе низкоуглеродистой стали 09Г2С, сверхнизкоуглеродистой стали 001ЮТ, алюминиевого сплава АМг3 и тепломорозостойкой резины В-14-1НТА методом горячего прессования с применением клея горячего отвержения. Выявлено влияние состава и конструкции композитов на ударную вязкость при температурах 20 и $-60^{\circ} \mathrm{C}$ и определены методом динамического механического анализа такие показатели демпфирующей способности материалов, как тангенс угла механических потерь $(\operatorname{tg} \delta)$, модуль упругости $\left(E^{\prime}\right)$ и модуль вязкости $\left(E^{\prime \prime}\right)$. Показана возможность использования слоистых металлорезиновых композитов, обладающих повышенным сопротивлением хрупкому разрушению в области низких климатических температур, а также в элементах конструкций транспортных систем с высокой вибрационной стойкостью.

Ключевые слова: слоистый металлорезиновый композит, горячее прессование, ударная вязкость, циклическое нагружение, динамический механический анализ, демпфирование. 


\section{1. Введение}

В настоящее время все более широкое применение в авиакосмической технике, автомобилестроении и транспортном машиностроении находят металлополимерные композиционные материалы благодаря возможности достижения в них уникального комплекса физико-механических и функциональных свойств [1-4]. Данные материалы характеризуются низкой плотностью, высокой удельной жесткостью и прочностью, повышенной стойкостью в агрессивных средах и одновременно обладают ярко выраженными вязкоупругими свойствами, что позволяет применять их в качестве вибродемпфирующих элементов и отказаться от создания специализированных систем демпфирования [5-6]. Металлополимерные композиты обладают сравнительно невысокой себестоимостью, а технология их получения не требует высоких давлений (не более 10-30 МПа) и температур [7]. Значительный практический интерес представляют демпфирующие металлополимерные материалы на основе резин, низкоуглеродистых сталей, алюминиевых сплавов со слоистой архитектурой, которые могут быть применены в деталях и узлах подвески автомобильного и железнодорожного транспорта, что обеспечит снижение веса конструкции или повышение амортизационных свойств подвески без усложнения конструкции. Металлорезиновые композиты рекомендуется использовать для строительства виброзащитного пути метрополитенов в качестве узлов конструкции рельсовых опорных блоков [8]. Двухслойные металлорезиновые соединения, применяемые в настоящее время в деталях железнодорожного транспорта, имеют проблему потери своих эксплуатационных свойств за счет быстрого износа и адгезионного отслоения резиновых слоев под действием постоянных циклических и динамических нагрузок. Применение новых составов материалов резин с различными антифрикционными наполнителями и модифицированным поверхностным слоем, а также использование новых адгезивов позволяют повысить срок службы металлорезиновых соединений [9]. Тем не менее, вопросы прочности и износостойкости металлорезиновых соединений изучены преимущественно на двухслойных композитах $[10,11]$, а данные по исследованию физико-механических свойств слоистых металлорезиновых композитов, состоящих из трех и более слоев практически отсутствуют в научной литературе. Важным преимуществом предлагаемой слоистой симметричная конструкция композита с жесткой внешней оболочкой в виде металлических слоев с морозостойкими резиновыми прослойками является возможность сохранения в них высокого сопротивления хрупкому разрушению при пониженных климатических температурах [12].

В связи с этим в настоящей работе проведено сравнительное изучение характеристик ударной вязкости и особенностей разрушения двух типов 5-слойных композитов на основе низкоугеродистых сталей 09Г2С и 001ЮТ, алюминиевого сплава АМг3 и тепломорозостойкой резины В-14-1НТА при комнатной и пониженной температуре, а также с использованием метода динамического механического анализа [13,14] определена способность данных материалов к демпфированию упругих колебаний.

\section{2. Материалы и методы исследования}

В качестве исходных металлических материалов для получения пятислойных металлорезиновых композитов разной конструкции были использованы низкоуглеродистая малолегированная сталь 09Г2С, сверхнизкоуглеродистая малолегированная сталь 001ЮТ (IF сталь) и алюминиевый сплав АМг3. Составляющие композиты металлические материала имели следующий химический состав (в масс.\%): сталь 09Г2С (Fе (осн.), $0.12 \% \mathrm{C} ; 1.32 \% \mathrm{Mn}, 0.68 \% \mathrm{Si}, 0.12 \% \mathrm{Cu}, 0.07 \% \mathrm{Cr}, 0.07 \% \mathrm{Ni}$, $0.04 \% \mathrm{Al}, \quad 0.02 \% \mathrm{P}, \quad 0.01 \% \mathrm{~S}, \quad 0.01 \% \mathrm{Mo}) ;$ сталь $001 Ю \mathrm{~T}$ (Fe (осн.), $0.0056 \%$ C, $0.123 \% \mathrm{Mn}, 0.055 \% \mathrm{Nb}, 0.053 \% \mathrm{Al}$, $0.044 \% \mathrm{Ti}, 0.023 \% \mathrm{Si}, 0.006 \% \mathrm{P}, 0.004 \% \mathrm{~S}$ ); алюминиевый сплав АМг3 (Al (осн.), 3.4\% Mg 0.6\% Si, 0.5\% Cu, 0.4\% Mn, $0.05 \% \mathrm{Cr}, \quad 0.2 \% \mathrm{Zn}, \quad 0.1 \% \mathrm{Fe}, \quad 0.1 \% \mathrm{Ti}$,). Полосы стали 001ЮТ и сплава АМг3 использовались в состоянии поставки, а стали 09Г2С после нормализации. Для определения химического состава материалов использовался оптический эмиссионный спектрометре SPECTROMAXX. В качестве промежуточной прослойки в конструкциях композитов использовалась тепломорозостойкая резина марки В-14-1НТА, рабочий интервал которой находится в диапазоне от -60 до $+100^{\circ} \mathrm{C}$. Получение пятислойных композиционных материалов на основе стали 09Г2С, 001ЮТ (IF сталь), алюминиевого сплава АМг3 и невулканизированной резины В-14-1НТА осуществлялось методом горячего прессования с использованием клея на основе дихлорэтана. Клей наносился на предварительно зачищенные и обезжиренные склеиваемые поверхности металлических полос. После выдержки полос на воздухе в течение 40 минут проводилось горячее прессование двух типов сборок композитов, где в качестве внешних и центральных слоев слоев использовались стальные и алюминиевые пластины, соответственно, а промежуточные слои были выполнены из резины (Рис. 1).

Процесс горячего склеивания заключался во взаимных полимеризационных процессах, возникающих в адгезиве и невулканизированной резине при повышенном давлении, и достижением температуры полимеризации. Для этого собранный пакет был помещен под пресс в специальную форму, препятствующую сдвигу слоев, и нагрет до температуры $145 \pm 5^{\circ} \mathrm{C}$. Давление прессования составило $7.5 \mathrm{MПа,} \mathrm{а} \mathrm{время}$ выдержки под давлением 40 минут. Полученные образцы композиционного материала охлаждались на воздухе до комнатной температуры и после этого извлекались из формы. Использованные для проведения испытаний ударные и разрывные образцы слоистых композитов были получены непосредственно методом горячего прессования и в дальнейшем не подвергались механической обработке.

Испытания слоистых композитов и стали основы 09Г2С на ударную вязкость по ГОСТ 9454-78 проводились 
при температурах +20 и $-60^{\circ} \mathrm{C}$ на инструментированном маятниковом копре IT 542M Tinius Olsen с максимальной запасенной энергией удара 543.7 Дж и ценой деления 1 Дж на образцах типа 11 размером $10 \times 10 \times 55$ мм с V-образным надрезом по «тормозящему типу» (с ориентацией линии надреза поперек слоев композита). В связи с тем, что толщина внешнего верхнего стального слоя композита составляла 2 мм, на ударные образцы наносился надрез глубиной 1.25 мм. Для достижения пониженной температуры $\left(-60^{\circ} \mathrm{C}\right)$ ударные образцы предварительно охлаждались и выдерживались в контейнере со смесью жидкого азота и бензина Калоша. Значения ударной вязкости усреднялись по результатам испытаний 3 образцов, разброс значений KCV не превышал 5\%. Для оценки демпфирующей способности слоистых композитов материалов методом динамического механического анализа (ДМА) при комнатной температуре на универсальной испытательной машине INSTRON 8801 нагрузочной способностью до 100 кН, точностью измерения нагрузок $\pm 0.5 \%$ и точностью измерения перемещений \pm 25 мкм проводились знакопеременные циклические испытания по схеме "растяжение-сжатие» с частотой 0.5 Гц и коэффициентом асимметрии цикла $R=-1$. Количество циклов нагружения составляло $N=100$ циклов. Использовались плоские образцы типа I (пропорциональные плоские образцы) по ГОСТ 1497-84 толщиной 10 мм, общей длиной 130 мм, шириной и длиной рабочей части 15 и 55 мм, соответственно.

Согласно приведенным в Табл. 1 результатам испытаний, образец стали основы композитов 09Г2С размером $10 \times 10 \times 55$ мм при комнатной температуре характеризуется более высоким уровнем ударной вязкости по сравнению с аналогичным образцом слоистого композита. Однако ударная вязкость стали с понижением температуры испытаний от +20 до $-60^{\circ} \mathrm{C}$ снижается почти в 3 раза, а образцов из слоистых композитов, напротив, возрастает примерно в 1.5 раза. Как видно из Рис. 2, при ударных испытаниях произошел только изгиб ударного образца, а его разделение на части и хрупкое разрушение какого-либо слоя не наблюдалось.

При пониженной температуре испытаний $\left(-60^{\circ} \mathrm{C}\right)$ разрушились только отдельные составляющие композита - слои сплава АМг3 и резины. На части ударных образцов композитов наблюдались отдельные отслоения с нарушением межслойных границ «металл-резина». Выявленное аномальное повышение значений ударной вязкости с понижением температуры можно объяснить наличием в композите прослоек из тепломорозостойкой резины и усилением при понижении температур испытаний характерного для материалов со слоистой архи-

\begin{tabular}{|c|c|}
\hline N & IF steel \\
\hline$N$ & rubber \\
\hline$\sim$ & $\mathrm{Al}-3 \mathrm{Mg}$ alloy \\
\hline$\sim$ & rubber \\
\hline$\sim$ & IF steel \\
\hline
\end{tabular}

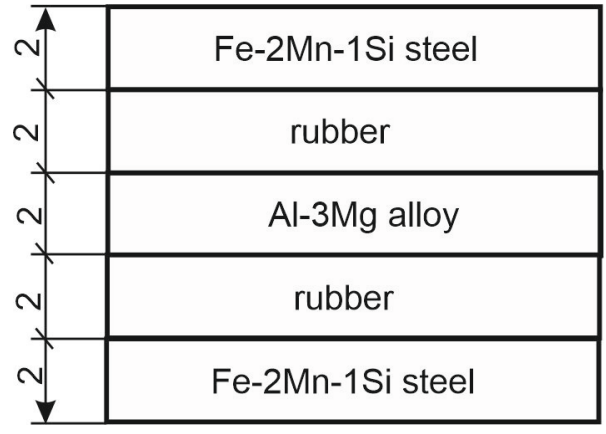

b

Рис. 1. Конструкции слоистых композитов: композит 1 (a); композит 2 (b). Цифрами обозначена толщина слоев в мм.

Fig. 1. Layered composite structures: composite 1 (a); composite 2 (b). The numbers indicate the thickness of the layers in $\mathrm{mm}$.

Табл. 1. Результаты ударных испытаний основы 09Г2С и слоистых композитов 1 и 2.

Table 1. Impact test results for Fe-2Mn-Si steel and layered composites 1 and 2.

\begin{tabular}{|c|c|c|c|}
\hline $\begin{array}{c}\text { Материал } \\
\text { Material }\end{array}$ & $\begin{array}{l}T, \text { град } \\
T, \text { deg }\end{array}$ & $\begin{array}{c}\mathrm{KCV}, \mathrm{MД} / \mathrm{M}^{2} \\
\mathrm{KCV}, \mathrm{MJ} / \mathrm{m}^{2}\end{array}$ & $\begin{array}{l}\text { Результат испытания } \\
\text { Result of test }\end{array}$ \\
\hline \multirow{2}{*}{$\begin{array}{c}\text { Сталь 09Г2C } \\
\text { Fe-2Mn-1Si steel }\end{array}$} & 20 & 0.85 & $\begin{array}{l}\text { Образец разрушился } \\
\text { Specimen is broken }\end{array}$ \\
\hline & -60 & 0.31 & $\begin{array}{l}\text { Образец разрушился } \\
\text { Specimen is broken }\end{array}$ \\
\hline \multirow{2}{*}{$\begin{array}{l}\text { Композит } 1 \\
\text { Composite } 1\end{array}$} & 20 & $>0.63$ & $\begin{array}{l}\text { Не разрушился ни один слой; локальные отслоения } \\
\text { No one layer is broken; local delamination }\end{array}$ \\
\hline & -60 & $>0.93$ & $\begin{array}{c}\text { Разрушились 2-й слой резины и 3-й слой АМг3; локальные отслоения } \\
2^{\text {nd }} \text { rubber layer and } 3^{\text {rd }} \mathrm{Al}-\mathrm{Mg} 3 \text { layer are broken; local delamination }\end{array}$ \\
\hline \multirow{2}{*}{$\begin{array}{l}\text { Композит } 2 \\
\text { Composite } 2\end{array}$} & 20 & $>0.44$ & $\begin{array}{c}\text { Не разрушился ни один слой; локальные отслоения } \\
\text { No one layer is broken; local delamination }\end{array}$ \\
\hline & -60 & $>0.60$ & $\begin{array}{c}\text { Разрушились 2-й и 4-й слои резины и } 3 \text {-й слой АМг3; локальные отслоения } \\
2^{\text {nd }} \text { and } 4^{\text {th }} \text { rubber layers and } 3^{\text {rd }} \mathrm{Al}-\mathrm{Mg} 3 \text { layer are broken; local delamination }\end{array}$ \\
\hline
\end{tabular}

Примечание: Знак KCV> означает, что полностью все слои композита не разрушились. 
тектурой эффекта «вязкости расслоения» («delamination toughening») $[15,16,17]$.

При знакопеременном циклическом нагружении образцов слоистых композитов по «мягкой» схеме (с контролем по нагрузке) при максимальной нагрузке в полуцикле растяжения и сжатия $12 \mathrm{\kappa H}$ и величине напряжения 80 МПа, отнесенного к сечению всего композита и не превышающего его предварительно определенный статический предел упругости, в течение всех 100 циклов нагружения были зафиксированы выраженные петли механического гистерезиса в координатах «напряжение-деформация».

При этом, как видно из Рис. 3 для композита 1 петля гистерезиса при максимальном напряжении полуциклов «растяжения - сжатия» в сечении образца \pm 80 МПа с ростом числа циклов от 1 до 100 существенно сужается, а для композита 2 сохраняется постоянной, что указывает на наличие в данном материале более высоковязкой составляющей (слоев стали 001ЮТ), обеспечивающей поддержание его демпфирующих свойств с увеличением числа циклов нагружения.

Для оценки характеристик демпфирующих свойств композиционных материалов согласно рекомендациям $[13,14]$ были построены графики зависимостей напряжения и деформации от времени при циклическом синусоидальном растяжении-сжатии (Рис. 4).

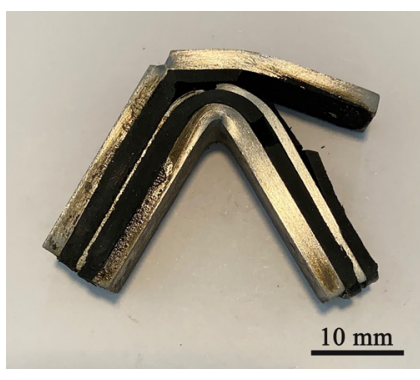

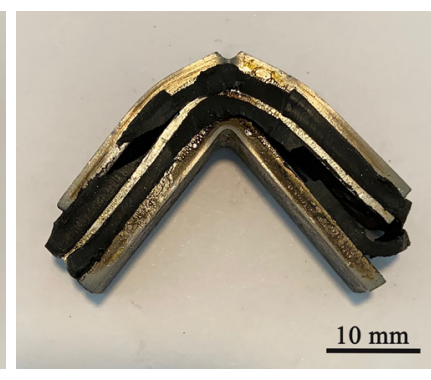

b
Как видно из Рис. 4 деформационный отклик композиционных материалов на приложенную нагрузку запаздывает во времени вследствие необратимых потерь энергии. В результате этого наблюдается фазовый сдвиг $\delta$ между приложенным напряжением и деформацией. Для оценки фазового сдвига $\delta$ между напряжением и деформацией по построенным синусоидам определена разница достижения максимумами $\varepsilon_{0}$ и $\sigma_{0}$ по времени. Расчет деформации выполняется согласно уравнению $\varepsilon=\sigma_{0} \sin \omega t / E=\varepsilon_{0} \sin (\omega t+\delta)$, которое с учетом наличия фазового сдвига, преобразуется в уравнение следующего вида:

$$
\varepsilon=\varepsilon_{0}[\sin (\omega t) \cos \delta+\cos (\omega t) \sin \delta] .
$$

Из этого следует, что деформация $\varepsilon$ может быть представлена как сумма двух составляющих модуля вязкости и модуля упругости [14]. Было установлено расстояние между ближайшими максимумами графиков синусоид, которое соответствовало углу сдвига фаз $\delta$. Затем были рассчитаны компоненты комплексного модуля упругости: модуля упругости $E^{\prime}=\left(\sigma_{0} / \varepsilon_{0}\right) \cos \delta$ и модуля вязкости $E^{\prime \prime}=\left(\sigma_{0} / \varepsilon_{0}\right) \sin \delta$.

Таким образом, проведенный динамический механический анализ экспериментальных данных циклического знакопеременного нагружения изученных слоистых композитов позволил определить важнейшие показатели

Pис. 2. (Color online) Вид боковой поверхности образцов слоистых композитов 1 и 2 после испытаний на ударную вязкость: композит 1 (a, b), композит 2 (c, d); температура испытаний $20^{\circ} \mathrm{C}(\mathrm{a}, \mathrm{c})$; температура испытаний $-60^{\circ} \mathrm{C}(\mathrm{b}, \mathrm{d})$.

Fig. 2. (Color online) The lateral side of composites 1 and 2 after impact tests: composite 1 (a, b), composite 2 (c, d); test temperature of $20^{\circ} \mathrm{C}(\mathrm{a}, \mathrm{c})$; test temperature of $-60^{\circ} \mathrm{C}(\mathrm{b}, \mathrm{d})$.

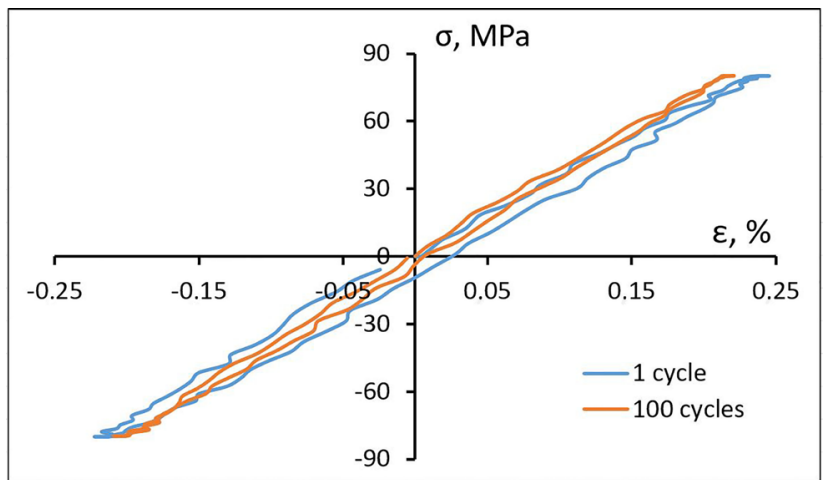

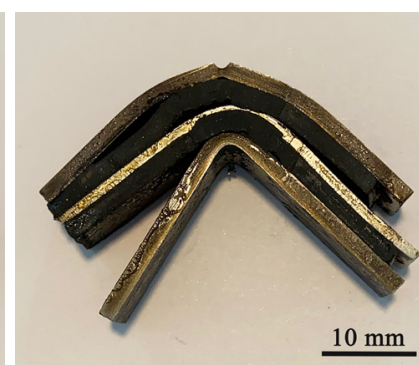

C

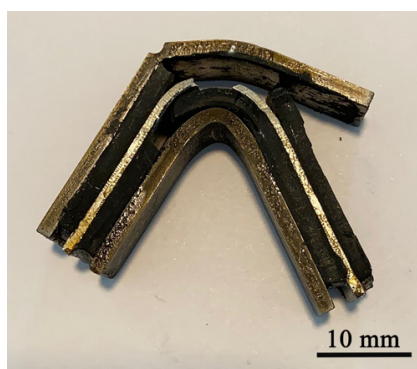

d 


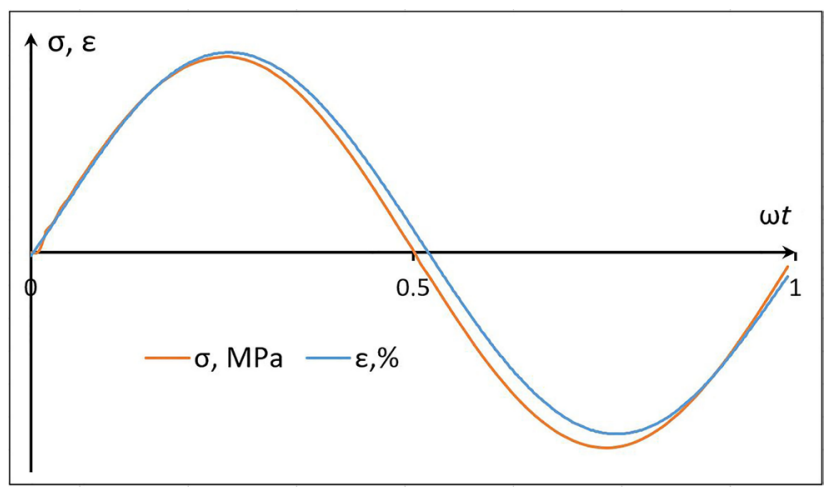

a

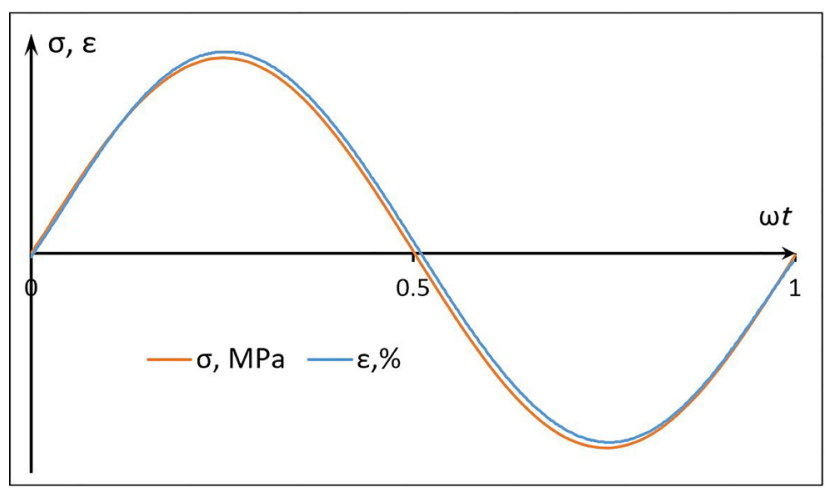

c

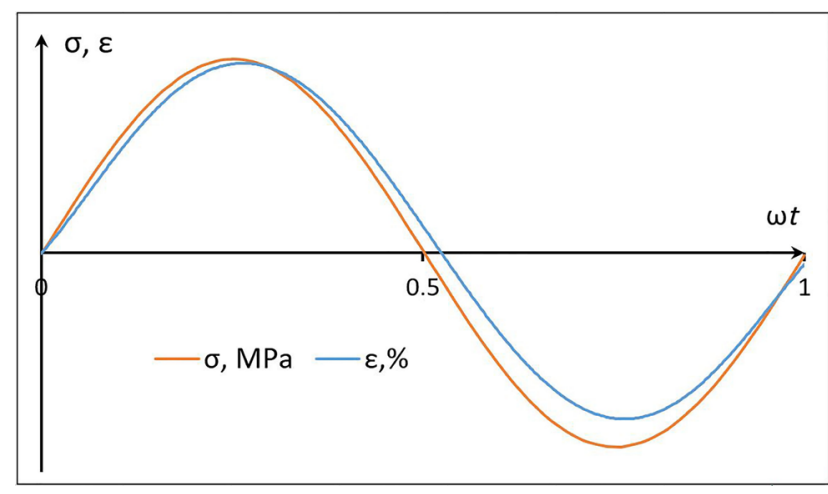

$\mathrm{b}$

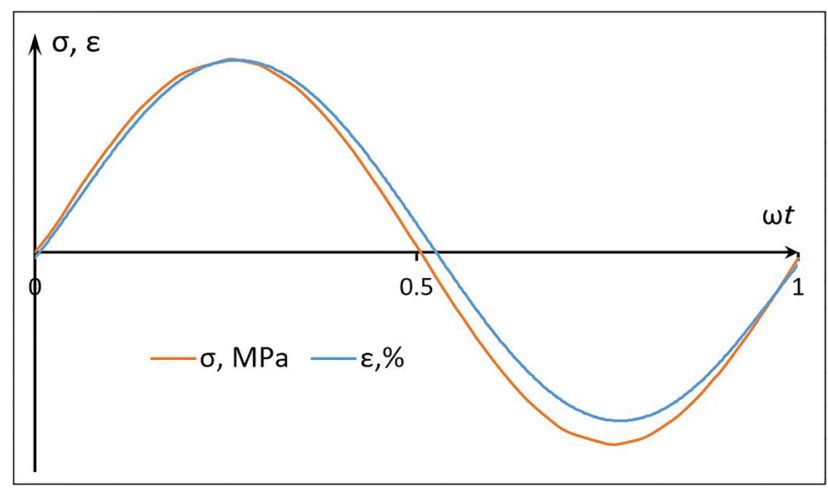

d

Pис. 4. (Color online) Синусоиды напряжения и деформации композита 1 после 1 цикла (а) и 100 циклов (с) нагружения и композита 2 после 1 цикла (b) и 100 циклов (d).

Fig. 4. (Color online) Stress and strain sinusoids of composite 1 after 1 cycle (a) and 100 cycles (c) of load and composite 2 after 1 cycle (b) and 100 cycles (d).

Табл. 2. Показатели демпфирующей способности композитов 1 и 2.

Table 2. Damping properties of composites 1 and 2.

\begin{tabular}{|c|c|c|c|c|c|c|c|}
\hline $\begin{array}{c}\text { Тип композита } \\
\text { Type of composite }\end{array}$ & $\begin{array}{c}\text { Число циклов } \\
\text { Number of cycles }\end{array}$ & $\varepsilon_{0}$ & $\begin{array}{l}\sigma_{0}, \mathrm{M \Pi а} \\
\sigma_{0}, \mathrm{MPa}\end{array}$ & $\begin{array}{c}\delta, \text { град } \\
\delta, \text { deg }\end{array}$ & $\begin{array}{l}E^{\prime}, \text { ГПа } \\
E^{\prime}, \mathrm{GPa}\end{array}$ & $\begin{array}{l}E^{\prime \prime}, \text { ГПа } \\
E^{\prime \prime}, \mathrm{GPa}\end{array}$ & $\operatorname{tg} \delta$ \\
\hline \multirow{2}{*}{ Композит 1 / Composite 1} & 1 & 0.003 & 79.86 & 4.59 & 26.60 & 1.08 & 0.04 \\
\hline & 100 & 0.003 & 79.17 & 4.59 & 26.37 & 0.90 & 0.04 \\
\hline \multirow{2}{*}{ Композит 2 / Composite 2} & 1 & 0.003 & 80.31 & 3.44 & 26.76 & 0.80 & 0.03 \\
\hline & 100 & 0.002 & 80.08 & 1.15 & 40.04 & 0.40 & 0.01 \\
\hline
\end{tabular}

демпфирующей способности материалов (Табл. 2), такие как тангенс угла механических потерь $(\operatorname{tg} \delta)$, модуль упругости $\left(E^{\prime}\right)$, модуль вязкости $\left(E^{\prime \prime}\right)$.

Приведенные в Табл. 2 результаты свидетельствуют о том, что композит 2 по сравнению с композитом 1 на всех циклах знакопеременного нагружения характеризуется более высокими значениями показателей демпфирования $\left(\operatorname{tg} \delta, E^{\prime}\right.$ и $\left.E^{\prime \prime}\right)$.

\section{3. Выводы}

1. Показана возможность получения методом горячего прессования новых слоистых композиционных материалов на основе низкоуглеродистых сталей, алюминиевого сплава и тепломорозостойкой резины, обладающих повышенным сопротивление хрупкому разрушению при низких климатических температурах и способностью к демпфированию упругих колебаний.
2. Выявлено аномальное повышение значений ударной вязкости изученных композитов с понижением температур испытаний от +20 до $-60^{\circ} \mathrm{C}$, связанное с усилением характерного для слоистых материалов эффекта «вязкости расслоения» и наличием в композите прослоек из тепломорозостойкой резины.

3. На основании экспериментально полученных петель механического гистерезиса и синусоид напряжений и деформация от времени методом ДМА определены основные параметры, характеризующие демпфирующую способность изученных слоистых металлорезиновых композитов (значения тангенса угла механических потерь и компонент комплексного модуля упругости).

4. Показано, что композит с внешними слоями из стали 001ЮТ по сравнению с композитом со слоями из стали 09Г2С сохраняет более высокие значения показателей демпфирования $\left(\operatorname{tg} \delta, E^{\prime}\right.$ и $\left.E^{\prime \prime}\right)$ на протяжении всех 100 циклов знакопеременного нагружения. 
Благодарности / Acknowledgements. Авторы выражают благодарность к.ф.-м.н. А.М. Пачелову за помощь в проведении горячего прессования для получения слоистых композитов. Исследование выполнено с использованием оборудования ЦКП «Пластометрия» ИМАШ урО РАН за счет гранта Российского научного боона (проект № 20-79-00084) в части изучения характеристик ударной вязкости и демпфирующей способности слоистых композитов и в рамках государственного задания ИМАШ урО РАН по теме №AAАA-A18-118020790147-4 в части отработки технологии получения слоистых материалов методом горячего прессования. / The authors are grateful to Ph.D. A.M. Patselov for assistance in obtaining of layered composites by hot pressing. The study was carried out using the equipment of the Shared Center "Plastometriya" of the Institute of Engineering Science UB RAS and supported by the Russian Science Foundation Grant (project no. 20-79-00084) in terms of studying of impact strength characteristics and damping properties of layered composites and in accordance of the state assignment of the Institute of Engineering Science UB RAS on topic No. AAAA-A18-118020790147-4 in terms of working out the technology for producing layered materials by hot pressing.

\section{Литература/References}

1. N. Chawla, K. N. Chawla. Metal matrix composites, 2nd ed. New York, Springer Science+ Business Media (2013) 370 p. Crossref

2. M.L. Kerber. Polymer composites: structure, properties, technology. St. Petersburg, CEP "Professiya" (2014) 592 p. (in Russian) [М.Л. Кербер. Полимерные композиционные материалы: структура, свойства, технология. Санкт-Петербург, ЦОП «Профессия» (2014). $592 \mathrm{c}]$

3. C. Bellini, V.D. Cocco, F. Iacoviello, L. Sorrentino. Frat. ed Integrita Strutt. 49, 739 (2019). Crossref

4. S. L. Bazhenov. Mechanics and technology of composites: scientific publication. Dolgoprudny, Publishing House "Intellect" (2014) 328 p. (in Russian) [С.Л. Баженов. Механика и технологии композиционных материалов: научное издание. Долгопрудный, Издательский дом «Интеллект» (2014). 328 с]

5. S.A. Chernikov, S. Samer. Vestnik MGTU im. N.E. Bauman. Ser. Instrumentation. 4, 111 (2006). (in Russian) [С.А. Черников, С. Самер. Вестник МГТУ им. Н.Э. Баумана. Сер. Приборостроение. 4, 111 (2006).]

6. S. A. Tipalin, B. Yu. Saprykin, N. F. Shpunkin. Izvestiya MSTU "MAMI". 2 (2), 194 (2012). (in Russian) [С.А. Типалин, Б. Ю. Сапрыкин, Н.Ф. Шпунькин. Известия МГТУ «МАМИ». 2 (2), 194 (2012).]
7. F. Matthews, R. Rawlings. Composites. Mechanics and technology. Moscow, Technosphere (2004) 408 p. (in Russian) [Ф. Меттьюз, Р. Ролингс. Композитные материалы. Механика и технология. Москва, Техносфера (2004) 408 с.]

8. M.N. Kolodkin, A.A. Zaitsev. Transport of the Russian Federation. 40-41, 74 (2012). (in Russian) [M.Н. Колодкин, А. А. Зайцев. Транспорт Российской Федерации. 40 - 41, 74 (2012).]

9. E. P. Tselykh, D.A. Polonyankin, E.A. Rogachev, V.I. Surikov. Omsk Scientific Bulletin. 137 (1), 97 (2015). (in Russian) [Е.П. Целых, Д.А. Полонянкин, Е.А. Рогачев, В.И. Суриков. Омский научный вестник. 137 (1), 97 (2015).]

10. A. B. Vetoshkin, S. V. Usachev, Gudkov S. V. Izv. Vyssh. Uchebn. Zaved. Khim. Khim. Tekhnol. 49 (10), 74 (2006). (in Russian) [А. Б. Ветошкин, С. В. Усачев, С. В. Гудков. Известия высших учебных заведений. Серия: Химия и химическая технология. 49 (10), 74 (2006).]

11. G. Polyzois, P. Lagouvardos, S. Zinelis, M. Frangou. Int. J. Adhes. Adhes. 30, 500 (2010). Crossref

12. S. V. Gladkovsky, P.D. Nedzvetsky, D.I. Vichuzhanin, S. V. Kuteneva, S. V. Lepikhin. DREAM. 2, 6 (2020). (in Russian) [C.В. Гладковский, П.Д. Недзвецкий, Д.И. Вичужанин, С.В. Кутенева, С.В. Лепихин. Diagnostics, Resource and Mechanics of materials and structures. 2, 6 (2020).] Crossref

13. V.A. Sagomonova, V.I. Kislyakova, T. Yu. Tyumenev, V.A. Bolshakov. VIAM Proceedings. 10, 63 (2015). (in Russian) [В.А. Сагомонова, В.И. Кислякова, Т. Ю. Тюменева, В. А. Большаков. Труды ВИАМ. 10, 63 (2015).] Crossref

14. Yu. V. Syty, V.A. Sagomonov, V.I. Kislyakova, V.A. Bolshakov. Aviation materials and technologies. 2, 51 (2012). (in Russian) [Ю. В. Сытый, В. А. Сагомонова, В.И. Кислякова, В.А. Большаков. Авиационные материалы и технологии. 2, 51 (2012).]

15. S. N. Sergeev, I. M. Safarov, A. V. Korznikov, R. M. Galeyev, S. V. Gladkovsky, D. I. Dvoynikov. Letters on Materials. 5 (1), 48 (2015). (in Russian) [С.Н. Сергеев, И. М. Сафаров, А. В. Корзников, Р.М. Галеев, С.В. Гладковский, Д.А. Двойников. Письма о материалах. 5 (1), 48 (2015).] Crossref

16. K. Babinsky, S. Primig, W. Knabl et al. JOM. 68 (11), 2854 (2016). Crossref

17. S. N. Sergeev, I. M. Safarov, A.P. Zhilyaev, R. M. Galeyev, S. V. Gladkovsky, D. I. Dvoynikov. Phys. Met. Metallogr. 122 (6), 665 (2021). (in Russian) [C.Н. Сергеев, И.М. Сафаров, А.П. Жиляев, Р.М. Галеев, С. В. Гладковский, Д. А. Двойников. ФММ. 122 (6), 665 (2021).] Crossref 